\title{
Políticas migratorias y dictadura militar en Argentina (1976-1983): la construcción de un modelo migratorio
}

\section{Lucila Sabrina Nejamkis*}

Perfiles Latinoamericanos, 24(47)

2016 | pp. 7-29

DOI: $10.18504 / \mathrm{pl} 2447-001-2016$

\section{Resumen}

Este artículo presenta el análisis del modelo migratorio instalado durante la dictadura militar argentina del periodo 1976-1983. La intención es evidenciar los cimientos con los que se "gestionó" la migración por más de 26 años. El interés se debe a que la disposición y continuidad de esta política pública generó una forma de tratar la migración limítrofe que actualmente, a pesar del cambio de política de 2003, aún repercute en la práctica cotidiana, tanto de los organismos públicos como de la población en general. Para establecer las relaciones propuestas, se trabajó mediante un diseńo metodológico cualitativo que combina el análisis sociojurídico y documental de la legislación y reglamentaciones con el método histórico-comparativo.

\begin{abstract}
This study analyzes the migratory model created during the last military dictatorship in Argentina (1976-1983), highlighting the foundation from where the migration was "managed" for over 26 years. It became into our interest because, although when the migratory policy changed in 2003, up today this former policy persists as a common practice for public agencies and the general population. To establish these relationships proposed, we worked with a methodology that combines the qualitative socio-legal analysis of documentations, legislation and regulations with the comparative historical method.
\end{abstract}

Palabras clave: políticas migratorias, proyectos de nación, Estado, dictadura militar, Argentina. Keywords: migratory policy, model of nation, State, military dictactorship, Argentina.

* Doctora en Ciencias Sociales por la Universidad de Buenos Aires. Investigadora Asistente (CONICET/ IDAes-unsam), Profesora Asociada Regular, Universidad Nacional Arturo Jauretche. 


\section{Introducción}

E

diciembre de 2003, el parlamento argentino aprobó la ley de migraciones $\mathrm{N}^{\circ} 25.871$, en reemplazo de la "Ley Videla" No 22.439 (1981), que había emanado de un gobierno de facto y que fue conocida por su alto carácter restrictivo y persecutorio en el tratamiento del fenómeno migratorio, especialmente el de origen latinoamericano. Si bien la actual legislación se destaca por el respeto a los derechos humanos de los migrantes, en este artículo interesa analizar el modelo migratorio que instaló la última dictadura militar a fin de evidenciar los cimientos con los cuales se "gestionó" la migración por más de 26 años. El interés se debe a que la disposición y continuidad de esta política pública generó una forma de tratar la migración limítrofe que actualmente, a pesar del cambio de política, aún repercute en la práctica cotidiana, tanto de los organismos públicos como de la población en general.

Por lo tanto, interesa esclarecer algunos de los criterios que funcionaron como bases para elaborar las políticas migratorias en Argentina entre 1976 y 1983. Si bien la política restrictiva hacia la migración limítrofe continuó en los gobiernos democráticos posteriores, importa centrarse en este periodo por la instauración de un modelo de "administración" de la población. Se entiende que en estas políticas se encuentra involucrada una idea de sociedad, de economía, de individuo, de política, de integración. En suma, un proyecto de nación.

En consecuencia, el eje de nuestro interés es el análisis de las políticas migratorias desarrolladas por la última dictadura militar con el objetivo de indagar en diversos interrogantes: ¿Con base en qué criterios y con qué tipos de argumentos el gobierno militar definió y ejecutó una determinada política migratoria? ¿Cuál es el ideal de sociedad que subyace a la misma? ¿Qué relaciones de poder se pretende perpetuar? ¿Cómo estos discursos se legitiman y perviven en una determinada época? Para establecer las relaciones propuestas, se trabajó mediante un diseño metodológico cualitativo que combina el análisis sociojurídico y documental de la legislación y reglamentaciones (Treves, 1988; Courtis, 2006) con el método histórico comparativo (Vior, 2007).

\section{Estado nación, proyectos nacionales y políticas migratorias}

Los científicos sociales que han estudiado las políticas migratorias se han basado tradicionalmente en diferentes presupuestos para entenderlas: los asentamientos poblacionales, las características deseadas o no de los migrantes, el impacto 
económico de las migraciones, y el papel de las migraciones en las relaciones entre países, entre otros. Sin embargo, a pesar de su importancia, estos aspectos son insuficientes para comprender en toda su complejidad el porqué de la puesta en práctica y mantenimiento de una determinada política migratoria, ni las influencias que ésta tiene sobre otros ámbitos políticos. Es decir, que para explicar la implantación y mantenimiento de una política migratoria es necesario atender un conjunto de aspectos interrelacionados, entre los que pesan las condiciones económicas y sociales, pero también las representaciones culturales y políticas, y las relaciones de poder entre sus actores.

En principio, no es posible pensar la inmigración - tal cual se la conoce hoy_ sin asociarla a los mecanismos de legitimación del Estado nación. Como plantea Sayad (1999), reflexionar sobre la inmigración y la emigración involucra los conceptos de Estado y nación, lo mismo que el modo en que ambos se construyen a sí mismos cuando piensan la inmigración. De acuerdo con esto, las diferentes respuestas a la inmigración se vinculan a las especificidades de los procesos históricos de formación de los Estados nacionales, a las formas de regulación de la admisión a la comunidad nacional, y a la variedad de derechos y obligaciones derivados de la pertenencia a la nación (Brubaker, 1992; López Salas, 2005).

Para analizar estas cuestiones resulta necesario un breve recorrido por las nociones de nación que fueron construidas históricamente por las ciencias sociales.

Durante el siglo xx, la idea de nación se definió como un conjunto de personas que comparten, además de un territorio y un Estado, una serie de rasgos culturales: una lengua, una religión, un modo de ver el mundo, una serie de tradiciones, etc. (Grimson, 2003; Segato, 2007). En los últimos 25 años, esta perspectiva se ha modificado y numerosos trabajos académicos propusieron el concepto de nación como una construcción cuyas tradiciones habrían sido inventadas o creadas de acuerdo con la legitimación de la propia idea de Estado como agente de soberanía (Anderson, 1993; Balibar, 1991; Grimson, 2003; Gil Araujo, 2006). En este contexto destaca la definición de Anderson (1993), para quien la nación es "una comunidad políticamente imaginada como inherentemente limitada y soberana"; "es imaginada porque aun los miembros de la nación más pequeña no conocerán jamás a la mayoría de sus compatriotas, no los verán ni oirán siquiera hablar de ellos, pero en la mente de cada uno vive la imagen de su comunión" (Anderson, 1993: 23). Esta transformación (de las características compartidas a la construcción) permitió enfocar los estudios académicos en los mecanismos de configuración nacional y en las disputas de poder, dominación y representación simbólica que involucra el concepto de nación. En resumen, las teorías constructivistas definen la construcción imaginaria del pueblo mediante la constitución imaginaria de la nación (Anderson, 
1993). A partir de "la comunidad imaginada" se distribuyen los derechos de los que pertenecen o no a dicha comunidad.

En esta línea de análisis, se deduce que el Estado nacional tiende a homogeneizar a su población, integrándola en patrones de vida considerados como "normales". Que es de este modo que crea las condiciones para el ejercicio de la ciudadanía, aunque para poder integrar necesita fijar los límites de la comunidad de los ciudadanos. Al establecerse las fronteras de la comunidad nacional y segregar a grupos poblacionales — a los que se atribuye determinadas características-, también se define en términos normativos cómo debe ser el ciudadano deseado. Es por esto que el estudio de la inmigración nos muestra cómo se conforma la ciudadanía, dado que es el hecho paradigmático que evidencia las reglas de funcionamiento de la nación y revela las bases de su constitución, instituyendo, asimismo, los criterios de inclusión y exclusión.

Para la operación con la que se construye una nación es indispensable, más que un territorio, la definición de un "pueblo" (Gil Araujo, 2006) que debe aparentar poseer una base étnica "natural", homogénea y homogeneizadora. Sin embargo, para sostener esta idea, se requiere que existan individuos o grupos que no se ajustan al modelo estipulado por el orden nacional. Los inmigrantes de hoy se transforman en ese "otro" para "asimilar" o "integrar", con lo que se muestra la naturaleza discriminadora de la forma nación y del Estado moderno.

Luego de analizar cómo la forma nación otorga sentido a las prácticas y discursos que reproducen un orden social, político, cultural y económico correlacionado con el modelo capitalista imperante, se recurre a la categoría de "proyecto nacional" para referirse a la estrategia social, cultural, económica, discursiva, política, histórica, internacional, etc. que, provista de cierta coherencia, implementa un conjunto de políticas para dar forma a un país, y que mediante un mecanismo identificatorio apela a la fuerza simbólica de la idea de nación como recurso ideológico fundamental para llevar a cabo dicha tarea. Este concepto combina elementos del pasado, del presente y, sobre todo, una relación con el futuro que se asocia a un conjunto de intenciones políticas que deben ser realizadas.

Por consiguiente, hay que contemplar la posibilidad de que históricamente los programas de gobierno no siempre hayan construido de igual manera, ni en forma homogénea o profunda, esta concurrencia de factores llamada "proyecto nacional”. En este sentido, plantear los proyectos nacionales como eje vertebral de nuestro análisis brinda pautas para indagar cómo los gobiernos legitiman y recrean un tipo de sociedad sobre la base de categorías nacionales.

De manera que estudiar las políticas públicas en torno a la migración es una de las formas para reflexionar sobre los proyectos de país, los modelos de sociedad y las relaciones de poder que cada gobierno pretende perpetuar. 


\section{Antecedentes del problema en Argentina y la política migratoria de la dictadura cívico-militar (1976-1983)}

Si bien el corpus empírico de este artículo se conforma de las políticas migratorias argentinas del periodo 1976-1983, para concebir la distribución etnocultural en la nación desde las políticas migratorias es importante resumir algunos patrones que han caracterizado a esta materia a lo largo de los ańos. Reflexionar sobre esta problemática conduce a alejarse en el tiempo, hasta esa suerte de ensueño en el que creyeron los argentinos descendientes de europeos sobre una migración "legal" e "ideal”. Un pasado idílico que se transformó en una imagen fundamental al momento de elaborar las políticas migratorias concretas.

Hasta 2003 — cuando se sanciona la actual ley migratoria $N^{\circ} 25.871$-, por diferentes causas, la inmigración europea había sido para los gobiernos la finalidad fundamental en el análisis de las políticas migratorias, aun cuando esto no se correspondiera con la realidad del país. Cabe destacar que el tratamiento de las migraciones fue una inquietud temprana del Estado argentino. Desde los inicios de la nueva república, las élites políticas argentinas insistieron en la importancia de la "calidad" de los flujos inmigratorios, a los que se asociaron orígenes nacionales y étnicos: por eso se insistió en atraer inmigrantes europeos (Cook, 2005: p. 4). La Constitución de 1853 ofrecía términos muy favorables para llevar a cabo este proyecto y eligió el ius solis (adoptar la nacionalidad por lugar de nacimiento) como el principio primario para determinar la pertenencia a la nación.

En este sentido, el artículo 25 de la Constitución establece el fomento a la inmigración europea. Por su parte, el artículo 20 hace referencia a los derechos de los extranjeros en el territorio de la nación consignando todos los derechos civiles del ciudadano.

En palabras de Cook (2005: p. 6), a partir de 1876 y con la sanción de la Ley de Inmigración y Colonización (Ley Avellaneda, No 817), se dio reconocimiento oficial y ayuda administrativa a las políticas migratorias precedentes que representaban un proyecto colonizador dirigido a poblar el interior del país a partir de la inmigración. ${ }^{1}$ Este hecho se enmarca en el periodo de pleno desarrollo del proyecto oligárquico que, según Botana, para la persistencia de su unidad política, encontraba tres problemas básicos que debía resolver: "1) integridad territorial; 2) identidad nacional; 3) organización de un régimen político" (Botana, 1994: p. 30).

1 Es preciso destacar que el territorio de la actual Argentina nunca estuvo despoblado. Metáforas como "poblar el desierto" sólo se usaron para justificar el despojo de los pueblos originarios y el genocidio. 
Por su parte, López Chirico (1985) entiende que esta etapa del Estado oligárquico corresponde al capitalismo temprano, cuando hay que disciplinar y generar mano de obra capitalista a través de la coacción extraeconómica. En el capitalismo desarrollado, esta tarea le incumbe a la coacción ideológico-económica.

Una prosperidad prolongada y sin igual, sumada a la afluencia de una masa inmigratoria abultadísima, cimentan las pretensiones de legitimidad natural del proyecto oligárquico argentino, fundado precisamente en la creencia de que su instauración ha llevado el país a la prosperidad. Al hacer suyos los preceptos de los liberales "civilizadores" y "modernizadores", la incorporación de la idea positivista de progreso que se difunde en las últimas décadas del siglo XIX facilita la legitimación de dicho proyecto oligárquico respecto de la masa inmigratoria cuyas motivaciones individuales se insertarían fácilmente dentro de los parámetros de aquél (López, 1985). Siguiendo esta fuente, se comprende que es clave la relación temprana entre los conceptos de migración y desarrollo, porque representa un claro ejemplo para pensar cómo, en pos de un proyecto de nación, desde las políticas migratorias se construye un modelo de sociedad de enclave con determinados sujetos considerados necesarios para realizar tal proyecto.

En este contexto, es pertinente destacar que si bien los inmigrantes que llegaron no fueron los que las élites políticas planeaban, es a partir de la Ley de Residencia de Extranjeros de 1902 (No 4.144) y de la Ley de Defensa Social de 1910 (No 7.209) que comienza a vislumbrarse un conjunto de normas restrictivas que rigieron en materia migratoria por más de cien ańos en Argentina — la Ley Avellaneda no mencionaba la posibilidad de ilegalidad en el ingreso o permanencia de los inmigrantes.

Según Olego de Campos (1990), desde 1923 se verifica un retroceso en materia de políticas migratorias, al sancionarse el primer reglamento migratorio que supuso la implementación de políticas de carácter restrictivo. Con éste se sistematizaron los criterios y normas selectivas referidos al ingreso de inmigrantes, lo que tenía en la mira la adecuación de las normas existentes sobre la entrada y la admisión de extranjeros. Olego de Campos entiende que desde ese momento el fenómeno migratorio se comenzó a regular por decretos del Poder Ejecutivo nacional (PEN) y por resoluciones de la Dirección Nacional de Migraciones (DNM), lo que impidió el necesario debate político y social.

A partir de 1943, un nuevo tipo de expansión económica se desarrolla en el país e incluye a protagonistas no nacionales (chilenos, paraguayos, bolivianos, uruguayos) que conformaban la "nueva inmigración": "La participación masiva de la población limítrofe en la transformación económica, política y social, junto con la población nativa, constituye la contrapartida de la segregación, también compartida, hasta ese momento" (Pérez Vichich, 1998: p. 449). En esta etapa, el ingreso desordenado de los inmigrantes limítrofes y el carácter de 
indocumentados de una buena parte de ellos se resolvieron con una amnistía inmigratoria en $1949,{ }^{2}$ de carácter histórico porque fue la primera otorgada y, a pesar de estar destinada sobre todo a los inmigrantes europeos de posguerra, benefició por extensión a los originarios de países vecinos y a los latinoamericanos no limítrofes. Con varias prórrogas, su vigencia concluyó en 1951 (Pérez Vichich, 1998).

Según Novick (1986), la idea de integración latinoamericana representa uno de los argumentos legitimadores de la política de amnistía que los gobiernos justicialistas emprendieron durante todos sus periodos en el poder. Por ese medio sancionaron normas referidas a los inmigrantes limítrofes puesto que la estrategia industrializadora necesitaba una mano de obra que los inmigrantes de los países vecinos podían satisfacer. Ello se refleja en las leyes $\mathrm{N}^{\circ} 14.345$ y $\mathrm{N}^{\circ} 14.392$, así como en los decretos $\mathrm{N}^{\circ} 15.972 / 49$ y $\mathrm{N}^{\circ} 13.721 / 51$ (Novick, 1986: p. 144). De acuerdo con esto, en las décadas de los cincuenta y los sesenta, sobre todo, se estabiliza la tendencia restrictiva en el tratamiento del fenómeno migratorio. Esto sucede en coincidencia con el cambio en la composición de los flujos migratorios, lo que implica una mayor visibilidad de los inmigrantes limítrofes. Una norma precursora en esta dirección fue el Decreto-Ley $\mathrm{N}^{\circ}$ $4.805 / 63$ que introduce la distinción entre los ilegales por ingreso (que entran por puntos no autorizados o eludiendo controles) y los ilegales por permanencia (que permanecen en el territorio argentino luego de vencido el plazo de permanencia autorizado). Por su parte, el reglamento migratorio de 1965 separa la admisión (consular) del ingreso y la permanencia. Asimismo, distingue entre admisión como residente permanente y no permanente, categorías a las que se asignan permisos de estancias y actividades diferenciales.

De igual modo, durante el gobierno de facto del general Onganía (1966-1970), el Decreto-Ley 17.294/67, sobre represión de la inmigración clandestina, enfatiza la prohibición de trabajo remunerado para extranjeros en situación irregular, y para residentes temporarios que carecieran de la habilitación de la autoridad migratoria, para los que autoriza su despido sin indemnización en el caso de no iniciarse su regularización en un plazo de tres meses (Courtis, 2006).

En resumen, como plantea Pacecca (2000), se identifican tres aspectos que caracterizan a este periodo: a) la normativa migratoria deja de expresarse en forma de leyes con trámite parlamentario regular para conformarse como un corpus asistemático y fragmentario dominado por los decretos del Poder Ejecutivo; $b$ ) este pasaje de leyes a decretos no sólo es paralelo a una política migratoria

2 En este contexto, no es un dato menor que el adjetivo "ilegal" que fue aplicado a ciertos tipos de inmigrantes residentes en el país, haya nacido con el decreto 1162 de 1949 y, desde entonces, siempre se encuentre presente en la normativa migratoria (Bonora, 2007). 
crecientemente restrictiva — aun cuando conviva con ocasionales amnistías-, sino que los decretos delegan un mayor poder de policía a instancias administrativas, $c$ ) se demuestra la notoria carencia de una legislación comprensiva que tome en cuenta las características de la migración limítrofe (Pacecca 2000: p. 8).

Vale por último aclarar que este proceso histórico funda las bases políticas e ideológicas sobre las que se asentará el tratamiento de las migraciones en el periodo posterior.

\section{La Junta Militar: hacia la construcción de un modelo migratorio}

Este breve recorrido histórico pretende contextualizar nuestro objeto de estudio: las políticas migratorias argentinas entre 1976 y 1983, entendiendo que la inscripción de la desigualdad etnocultural en la imagen de nación - a través de las políticas migratorias - constituye uno de los mecanismos utilizados por los distintos gobiernos para legitimar un discurso homogeneizador. Es fundamental profundizar en el análisis del contexto político, porque define las características del nacionalismo que se manifiesta en las discusiones sobre inmigración y minorías. Así pueden vincularse aquellas experiencias históricas con procesos políticos más recientes, como el antecedente fundamental de la Ley de Inmigración y Colonización (1876) que, a pesar de sus diversas regulaciones, se modificó hasta muchos años después por un gobierno militar. Como se verá, la transformación de esta norma en ese momento histórico encuentra clara vinculación con las ideas rectoras que sostenía y procuraba instalar la Junta Militar de 1976 como parte de su proyecto nacional: por ejemplo, las pretendidas "bases étnicas" sobre las que no sólo se erigió, sino que también se seguía pensando la "nación" argentina. En esa misma lógica, se establecieron las pautas de aquellos "sujetos de la nación" que implicaban una distribución de roles para implementarse en el orden político.

En efecto, las políticas migratorias de la dictadura cívico-militar (1976-1983) fueron del todo funcionales a un modelo de sociedad que la Junta intentaba imponer mediante el terrorismo de Estado. A la aspiración de establecer un gobierno de las Fuerzas Armadas se sumó el objetivo de producir un cambio profundo en la sociedad argentina. Cavarozzi (2002) caracteriza a este régimen como "autoritario refundacional", por su propósito de transformar al conjunto de la sociedad argentina e imponer un orden económico y social ortodoxo que eliminara todo vestigio de las políticas del peronismo.

Concretamente, las Fuerzas Armadas se propusieron un ambicioso plan de gobierno que incluía, entre otros, los siguientes puntos: reorganizar la nación, renovar sus estructuras económicas, reformar las instituciones políticas, trans- 
formar el orden jurídico, y dar nuevos contenidos a los valores establecidos en el preámbulo constitucional (Escude \& Cisneros, 2000: p. 20).

Así es como este proyecto nacional planteó transformaciones decisivas para la historia del país: a) un nuevo modelo de acumulación basado en un capitalismo rentístico-financiero que fracturó la clásica relación entre economía y sociedad; b) un cambio sustancial en el conjunto de relaciones sociales, organizado en torno a la lucha contra un Otro enemigo (el "terrorismo subversivo") que militarizó las relaciones sociales; c) una manera de ejercer un poder omnímodo por parte de las fuerzas militares y policiales basado en el discurso de mandoobediencia; $d$ ) un modo específico de castigo relacionado con la clandestinidad y la desaparición de personas; $e$ ) la apelación a una imagen de nación y a un pueblo caracterizados por la homogeneidad en su composición (cristiana, occidental, blanca, europea); $f$ ) un tipo ideal de individuo, un "Otro" encarnado fundamentalmente en la figura del subversivo que se reproduce en muchos Otros, entre los que los inmigrantes ocupan un lugar significativo.

Los analistas coinciden en que el proyecto instaurado por la Junta Militar se compara en su significado a los de 1880 y de 1930, porque instaló un modelo de acumulación que se distingue por sus constantes destructivas: desindustrialización selectiva, desocupación estructural, descenso integral de las clases subalternas, desguace del patrimonio estatal, decadencia de las prestaciones sociales, endeudamiento externo, fuga de capitales, primacía de las ganancias financieras y concentración del ingreso (Sirlin, 2007: p. 369).

En líneas generales, la política económica de esta etapa se basó en la desindustrialización, la concentración del capital, la liberalización de los principales mercados internos y una mayor vinculación con los mercados internacionales. La reforma financiera tuvo un papel determinante sobre la economía: entre 1975 y 1983, el sector de la construcción se contrajo 30\% y el empleo industrial en $40 \%$, los establecimientos productivos se redujeron $18 \%$, mientras que el sector financiero fue el de mayor crecimiento (Rapoport, 2006: p. 791).

El criterio de proteger la industria se reemplazó por el de premiar la "eficiencia”. Por lo tanto, se dejó de creer que el crecimiento económico y el bienestar social se asociaban a la industria (Romero, 2005). La ideología dominante propugnaba porque el Estado abandonara las actividades en las que el mercado podía desempeñarse más "eficientemente".

El papel del sistema financiero se modificó, lo que provocó la transferencia de recursos desde la industria hacia las actividades financieras. El resultado fue un profundo cambio en el comportamiento de las empresas industriales, arrastradas a una lógica de corto plazo, en la que lo financiero predominaba sobre lo productivo (Rapoport, 2006: p. 794). De acuerdo con esta lógica, la industrialización por sustitución de importaciones había sido definitivamente 
desarticulada y, mientras desaparecían ramas enteras de la producción, se comprimió el mercado interno a niveles inimaginables. ${ }^{3}$

Según Ferrer (2009), el desmantelamiento industrial y el aumento del desempleo tuvieron las consecuencias regresivas más profundas y prolongadas sobre la distribución del ingreso. Hicieron crecer la población en situación de pobreza crítica (Ferrer, 2009: p. 390) y, en este sentido, el periodo se caracterizó por la movilidad social descendente de las clases obrera y media (Rapoport, 2006).

Estos cambios no fueron el producto de fuerzas impersonales y automáticas, sino que requirieron una fuerte intervención del Estado. Las transformaciones llevadas a cabo por José Alfredo Martínez de Hoz (ministro de Economía durante los cinco años de la presidencia de Videla) no buscaban la fórmula del crecimiento, sino la del orden y la seguridad. La "panacea" consistía en suplir la dirección del Estado por la del mercado. Por ello, buena parte de la política se orientó a desmontar los instrumentos de dirección, regulación y control de la economía que se habían construido desde 1930: el control de cambio, la regulación del crédito, la tasa de interés y la política arancelaria (Romero, 2005: p. 222).

A partir de estos datos resulta pertinente preguntarse por el lugar de los inmigrantes en el modelo, teniendo en cuenta que en la composición de la población se incluía una inmigración limítrofe, cuya inserción laboral se inscribía en las ramas productivas que el desempleo más había reducido y afectado. En efecto, la población migrante integraba los segmentos del mercado laboral atrasados, de poca calificación y de bajos ingresos.

Desde el punto de vista del sistema económico —el cual entonces destruía ramas enteras de la industria y la producción acrecentando la pobreza-, la intervención del Estado en materia migratoria se volvía necesaria. En primera instancia se puede afirmar que si bien los trabajadores limítrofes eran no deseados, tanto desde la normativa como desde la discriminación cotidiana, esa ilegalidad que se les atribuía servía para explotarlos y maltratarlos más (Pérez Vichich, 1988). Todos los inmigrantes regulares o irregulares tributan enormemente al IVA y a todos los impuestos al consumo, igual que el resto de la población. Con su trabajo aportan valor a las cadenas productivas, sin embargo, en general, su retribución es diferencialmente más baja que la del resto. Por eso, si hay sujetos

3 Rapoport explica que no todos los sectores se vieron afectados de la misma manera. Los vinculados principalmente al mercado interno o que competían con las importaciones sufrieron un derrumbe muy pronunciado; por ejemplo, el sector de la construcción se contrajo casi 30\% en el periodo 1975-1983. La industria mostró un comportamiento fluctuante, pero disminuyó en $12.4 \%$. Por el contrario, el sector agropecuario y la minería se expandieron debido a su mayor inserción exportadora (Rapoport, 2006: p. 802). 
que aportan económicamente al país — sin una contraprestación estatal y patronal acorde—, ésos son los migrantes —en especial, los irregulares.

En este contexto, un elemento fundamental para pensar las políticas migratorias es el recetario liberal de 1976 y su énfasis en la idea de "Estado fuerte". 4 Contrariamente a lo que pudiera suponer una visión poco informada sobre el liberalismo argentino, se evidencia que los temas poblacionales ocupaban un lugar privilegiado en el proyecto político del gobierno militar y el "disciplinamiento" social era uno de los que el régimen tenía en cuenta. Así, las políticas de población se convierten en herramientas fundamentales para cumplir sus objetivos.

La participación del Estado coincidió también con la forma de legislar la cuestión migratoria a través de leyes concretas que rompieron el círculo de decretos mediante los que se regulaba la Ley Avellaneda hasta ese momento.

A su vez, estas políticas migratorias encontraron sustento en los documentos y en las bases políticas de las Fuerzas Armadas para el Proceso de Reorganización Nacional, donde se evidencia la importancia de instalar y mantener una determinada mirada sobre la que erigir la imagen nacional argentina y, por consiguiente, el carácter del "pueblo" que debía componer la nación. Esto legitimaba a determinados sujetos con el interés de generar efectos universalizantes a niveles sociales, culturales y políticos.

El proyecto nacional que se quiso imponer combinaba una mitología nacionalista católica con la retórica sobre la eficiencia militar. Con estas condiciones, la imagen nacional argentina se fue transformando: la construcción de "pueblo" fue haciéndose estamental y jerárquica. El 24 de marzo de 1976, en el acta que fijó los propósitos y los objetivos básicos para el Proceso de Reorganización Nacional, se dejaron sentadas las intenciones de esta propuesta política:

Restituir los valores esenciales que sirven de fundamento a la conducción integral del Estado, enfatizando el sentido de moralidad, idoneidad y eficiencia, imprescindible para reconstruir el contenido y la imagen de la nación, erradicar la subversión y promover el desarrollo económico de la vida nacional basado en el equilibrio y participación responsable de los distintos sectores a fin de asegurar la posterior instauración de una democracia republicana, representativa y federal, adecuada a la realidad y exigencias de solución y progreso del pueblo argentino. (Documentos Básicos y Bases Políticas de las Fuerzas Armadas para el Proceso de Reorganización Nacional, p. 7).

4 Cavarozzi aclara que los teóricos originales del liberalismo y también los que lo practicaron desencadenaron la articulación de una sociedad capitalista moldeada por la economía de mercado no como un proceso natural, sino como puesto en marcha por el Estado. 
En los objetivos mismos del documento se marcan las necesidades de una soberanía política basada en los valores de la moral cristiana, la tradición nacional y el ser argentino, y la seguridad nacional, entre otras:

[La] Creación de una soberanía política basada en el accionar de instituciones constitucionales revitalizadas, que ubiquen permanentemente el interés nacional por encima de cualquier sectarismo, tendencia o personalismo [...] Vigencia de los valores de la moral cristiana, de la tradición nacional y de la dignidad del ser argentino [...] Vigencia de la seguridad nacional, erradicando la subversión y las causas que favorecen su existencia [...] Concreción de una situación socioeconómica que asegure la capacidad de decisión nacional y la plena realización del Hombre argentino; en donde el Estado mantenga el control sobre las áreas vitales que hacen a la seguridad y el desarrollo [...] Relación armónica entre el Estado, el capital y el trabajo, con fortalecido desenvolvimiento de las estructuras empresariales y sindicales ajustadas a sus fines específicos (Documentos Básicos y Bases Políticas de las Fuerzas Armadas para el Proceso de Reorganización Nacional, p. 7).

En estas premisas se observa la idea de refundar la comunidad, lo que incluye la prefiguración de lugares para los diferentes Otros de la nación y la idea de una "esencia" del hombre argentino: blanco, cristiano, occidental, hombre, adulto, propietario. La contraposición es ese "otro", cuyo asidero no sólo era el subversivo, sino también el inmigrante. A su vez se reconoce una clara apelación al "pueblo" como parte constitutiva de la nación. Dentro de la proclama se formula una convocatoria a la comunidad nacional, como si ésta representara un todo homogéneo, libre de cualquier fisura, y se exceptuara a aquéllos que fueron acusados de subvertir el orden pensado:

Nuestro pueblo ha sufrido una nueva frustración [...] Las Fuerzas Armadas han asumido el control de la República. Quiera el país todo comprender el sentido profundo e inequívoco de esa actitud, para que la responsabilidad y el esfuerzo colectivo acompañen esta empresa que, persiguiendo el bien común, alcanzará — con la ayuda de Dios- la plena recuperación nacional (Documentos Básicos y Bases Políticas de las Fuerzas Armadas para el Proceso de Reorganización Nacional, pp. 11-12).

Asimismo, entre las bases políticas que datan de diciembre de 1979 se entiende como valores esenciales la concepción cristiana de la vida y las tradiciones culturales:

Los valores esenciales que dan fundamento a la conducción del Estado han sido restituidos; y sobre ellos se ha reconstituido el contenido de la imagen de nación 
[...] Será preciso simultáneamente impulsar un nuevo ciclo de desarrollo integral, político, social y económico, sustentado en los dos pilares inconmovibles de nuestra nacionalidad: la concepción cristiana de la vida y las tradiciones de nuestra cultura (Documentos Básicos y Bases Políticas de las Fuerzas Armadas para el Proceso de Reorganización Nacional, p. 43).

Esto evidencia que antes de sancionada la Ley de Fomento de la Inmigración ya se tenían lineamientos sólidos sobre lo que debía representar el "ser nacional", basado en la concepción cristiana y las "tradiciones" de "nuestra" cultura. Con estos objetivos en mente una de las formas de fortalecer esa imagen nacional consistía en establecer políticas públicas concretas relativas a la inmigración.

Entre los conceptos rectores en que estas políticas se basan no puede faltar una conciencia histórica con fundamento en la cultura y las tradiciones: "La nación se ha estructurado a través de muchos años de vida y los argentinos tienen una conciencia histórica, una cultura, tradiciones, y creencias propias, un estilo de vida singular, glorias, héroes y mártires comunes, y han realizado juntos grandes empresas y conservan vigorosa la voluntad para realizarlas en el futuro" (Documentos Básicos y Bases Políticas de las Fuerzas Armadas para el Proceso de Reorganización Nacional Bases para la reorganización nacional: p. 47).

Es llamativo que se invoque también el preámbulo de la Constitución $\mathrm{Na}$ cional: "La nación expresa sus fines en el preámbulo de la constitución nacional: afianzar la justicia, consolidar la paz interior, proveer a la defensa común, promover el bienestar general y asegurar los beneficios de la libertad". No obstante que justamente se omita el pasaje que expresa "para todos los hombres del mundo que quieran habitar en el suelo argentino" (Bases para la reorganización nacional: p. 47).

Las bases del Proyecto permiten evidenciar su sostén ideológico-político, pues son reiteradas las convocatorias nacionales del régimen contra un enemigo ${ }^{5}$ construido y, por contraposición a éste, la apelación a la esencia de ser un "buen argentino".

5 Es importante destacar que el concepto de enemigo interno cobra en la Argentina un papel fundamental ya que la política de desaparición sistemática de personas — original del modelo argentino — repercute no sólo sobre integrantes de una organización político militar, sino también sobre cualquier persona que, para las Fuerzas Armadas, pueda ser considerada colaboradora o perturbadora de la sociedad occidental y cristiana: obreros, empresarios, sacerdotes, deportistas, conscriptos, artistas, periodistas, personas vinculadas a ámbitos educativos, etc. Diferentes trabajos han seńalado que la figura del enemigo interno ha sido una condición de posibilidad del desarrollo del genocidio en tanto categoría que opera una delimitación, marcaje y exclusión de un "otro" que puede ser exterminado (Feierstein, 2007; Calveiro, 1998; Duhalde, 1999). 
En este entramado complejo de relaciones sociales, resulta interesante pensar cuál era el lugar de los inmigrantes y hasta qué punto no fueron constituidos en la misma línea de los "insurgentes subversivos", en el sentido de un "otro" externo a la comunidad nacional. Este "otro", por consiguiente, ponía en riesgo la supuesta homogeneidad ficticia del ser argentino y de la imagen nacional que los discursos del gobierno pretendían reforzar con tanta intensidad.

De acuerdo con Grimson (2003), la inmigración como problema social expresa transformaciones profundas en la sociedad argentina. En este sentido, el gobierno militar puso en marcha un periodo caracterizado por la movilidad social descendente de las clases obrera y media a través de la adopción y la profundización de políticas de corte neoliberal. Así, los nuevos problemas de clase impactaron sobre los discursos vinculados con los inmigrantes y con la etnicidad. No es casual que este proceso sea simultáneo a la fractura de la imagen de nación "europea" construida por la élite oligárquica entre 1853 y 1880. La combinación de represión, transnacionalización cultural, retroceso económico y exclusión social deslegitimó el mito argentino "[...] que suponía que la mezcla de poblaciones europeas en el país produciría un progreso escalonado de generación en generación" (Vior, 2006: p. 20).

Tal como plantea Grimson (2003), entre 1945 y 1976 los inmigrantes latinoamericanos fueron incorporados dentro de los "cabecitas negras". ¿Qué pasa cuando las transformaciones en la sociedad son tan profundas que no se sabe bien a qué colectivo incorporarlos? Aquí se cruzan conceptos sugestivos como el de "nacionalidad" y el de "clase social", que invitan a reflexionar sobre la discriminación estatal y la de la comunidad de recepción. Las políticas migratorias condensan un modelo de sociedad, una imagen nacional, un sujeto ideal que debe circunscribirse al ámbito nacional. Para pensar esta problemática, parece adecuado centrarse en la normativa emanada del gobierno de facto, en tanto representa una expresión ideológica que cristaliza un sistema de valores y un sistema simbólico que se reproducen a través de éstos. Por otro lado, resulta apropiado destacar que la organización jurídica de este periodo es confusa: se mezclaron leyes, decretos y reglamentos sin criterio alguno, así como no quedó en claro quién dictaba cada norma ni cuál era su alcance. Hubo una notoria reticencia a explicitar los fundamentos de estos documentos y, en ocasiones, hasta se mantuvo en secreto su misma existencia. Se prefirieron las normas legales onmicomprensivas y habitualmente se otorgaron facultades amplias a los órganos de aplicación, pero además se toleró su permanente violación o incumplimiento. Todo el edificio jurídico de la República resultó contaminado por el Estado terrorista clandestino, a tal punto que prácticamente no hubo límites normativos para el ejercicio del poder, convertido en potestad omnímoda del gobernante (Groisman, 1983). 
Las investigaciones que han analizado en profundidad las políticas migratorias de este periodo (Novick, 1986; Pérez Vichich, 1988; Sassone, 1987; Olego de Campos, 1990) coinciden en caracterizarlas como altamente restrictivas respecto al ingreso de inmigrantes limítrofes, ampliatorias de las capacidades del Poder Ejecutivo para expulsar población y cada vez más controladoras. No es casual que el Proceso de Reorganización Nacional haya sido el único que legisló sobre las políticas de población en forma global con el Decreto 3.938/77, en el que se aprueban los objetivos y las políticas nacionales de población ${ }^{6}$ (Novick, 1992).

El estudio de esa norma resulta de sumo interés, porque conduce a reflexionar sobre las estrategias políticas elaboradas desde el gobierno militar para inmiscuirse y participar en cada una de las áreas poblacionales, con el fin de controlar a la población en su totalidad desde el Estado. Dicho Decreto dispone que "[...] la Comisión Nacional de Política Demográfica informará cuatrimestralmente al Poder Ejecutivo, por medio del Ministerio del Interior, acerca del estado de elaboración y cumplimiento de la política de población”. Por otro lado, dentro de los objetivos y políticas nacionales de población, destacan:

1) El crecimiento cuantitativo y cualitativo de la población, para que Argentina pueda desarrollarse plenamente como comunidad nacional y cumplir un papel relevante en América Latina y en el mundo; 1.2.) Elevar la calidad de su población en cuanto a cultura, salud, educación y capacitación, eficiencia económica y espíritu de empresa y otros atributos, preservando la unidad y los valores nacionales.

Asimismo, esboza algunos lineamientos esenciales de la futura Ley Videla, ya que expresa claramente la selección de un "tipo" de migrante y el intento de direccionar esa migración a distintas zonas del país y a diferentes sectores del mercado de trabajo:

4.3) incrementar la inmigración con un mínimo de selección que asegure condiciones de salud y características culturales que permitan su integración en la sociedad argentina; 4.3.1.) determinación de áreas territoriales estratégicas, según necesidades, condiciones de explotación e infraestructura, que permitan la más conveniente distribución y radicación de la población inmigrante, facilitando la integración con grupos nativos y evitando la formación de colectividades cerradas;

6 Este decreto se sancionó durante el gobierno de Isabel Martínez de Perón. Al mismo año corresponde el Decreto 464/1977, el cual determina que: "Los programas especiales de radicación e instalación de extranjeros en la R.A. destinados a tareas profesionales y otras de interés para el país, serán evaluados y aprobados por la Subsecretaría de Asuntos Institucionales del Ministerio del Interior y para argentinos del mismo temperamento". 
4.3.3) atraer la inmigración de contingentes calificados y facilitar el ingreso de migrantes con capital; 4.3.2.) Política de creación de fuentes de trabajo, que contemple la incorporación de la mano de obra inmigrante; 4.3.4) disposiciones destinadas a facilitar el ingreso de inmigrantes con capital; 4.3.5) organización de un régimen de ingreso que permita la adecuada selección y encauzamiento de los inmigrantes de países limítrofes.

Como explica Pérez Vichich (1988), este instrumento responde a un concepto de homogeneidad étnica y a un prejuicio antilatinoamericano; según éstos, no habría en el país suficientes trabajadores calificados, técnicos y profesionales de origen europeo y por ello debía estimularse su inmigración. La inmigración de trabajadores no calificados de países limítrofes era significativa en términos de volumen, pero no se deseaba. La prioridad dada a los inmigrantes europeos se justificaba "procurando mantener la composición étnica del país" (Pérez vichich, 1988: p. 445).

El análisis de esta primera norma permite comprender cómo la población se convirtió en un fin y en un objeto de intervención del gobierno militar. Centrar las políticas migratorias en el eje de la seguridad se transformó en un problema policial, porque consistía en un asunto de control de las poblaciones. El proceso militar fue un gran experimento disciplinador desde lo alto y sobre la sociedad (Novaro \& Palermo, 1996). En efecto, en el caso migratorio se evidencia cómo en pos de un proyecto político se gestiona la diversidad y con ella la población considerada como "adecuada" para componer una determinada imagen de nación.

En síntesis se observa el tinte discriminador y eurocentrista del mencionado decreto, al igual que la ideología de quienes gobernaban el Estado represivo en aquel entonces. En torno a un conjunto de construcciones gubernamentales (la unidad y los valores nacionales, la homogeneidad en las características culturales de la población argentina, la existencia de "grupos nativos europeos", las colectividades cerradas, la integración, los inmigrantes limítrofes, la inmigración con capital, etc.), se comienza a conformar el edificio jurídico ideológico sobre el que se erigirá el universo de políticas públicas en materia migratoria en los veinte ańos posteriores.

A la normativa migratoria se suman las leyes de ciudadanía y naturalización. Estas categorías son fundamentales para pensar un proyecto nacional, en tanto develan cuestiones profundas relativas al momento de planear la construcción de un orden político en el que se inscriba una determinada identidad nacional. El gobierno militar también realizó modificaciones en este aspecto: en 1978 se reemplaza la Ley $\mathrm{N}^{\circ} 346$ de Ciudadanía y Naturalización — que, con diversas regulaciones, había sobrevivido desde 1869 — por la Ley $\mathrm{N}^{\circ} 21.795$ en la que 
se observa tanto al tipo de ciudadano que se pretendía moldear a través de la normativa, como al tipo de inmigrante que la Junta Militar consideraba "adecuado" para habitar en el país. En el capítulo II del Título I de la citada ley ("De los argentinos naturalizados") se puede destacar el artículo 5 que trata de los requisitos que deben cumplir los extranjeros para obtener la nacionalidad, por ejemplo, tener medios honestos de vida, saber el idioma nacional, conocer los principios de la Constitución argentina, entre otros.

En 1981 y como parte de este proyecto se sancionó el Decreto-Ley N²2.439 de migraciones y fomento de la inmigración, conocido como Ley Videla. Ésta cristaliza los discursos relacionados con la necesidad del gobierno de imponer barreras al avance de "ideologías extrañas", pero también se vincula a una pretendida homogeneidad étnica supuesta en la población argentina. El proyecto de nación sostenido desde el régimen abogaba claramente por el mito constitutivo de la inmigración europea como la población que siempre existió y debía permanecer para constituir la nación. Este tipo de normativa desconoce la existencia de pueblos originarios y se nutre de aquellos imaginarios sociales que ubican los orígenes del pueblo argentino exclusivamente en la inmigración europea. Así, en el artículo 2, esa ley ratifica el fomento a la inmigración extranjera " $[\ldots .$.$] cuyas características culturales permitan su adecuada integración$ en la sociedad argentina”. Otorga prioridad a los inmigrantes europeos con la pretendida justificación de mantener la composición étnica del país.

Ningún capítulo de dicha norma menciona los derechos de los extranjeros; por el contrario, el Estado se instituye en una relación unilateral en la que el inmigrante sólo es objeto de derecho, pero no su sujeto. En este sentido, el artículo $7^{\circ}$ establece, entre otras cosas, la idea de algún tipo de beneficio que los inmigrantes debían aportar al país:

Para alcanzar los fines previstos en el Artículo 2 y con sujeción a las pautas generales que fije el Poder Ejecutivo, el Ministerio del Interior podrá: i) con intervención de las Provincias interesadas y de los organismos nacionales competentes, auspiciar la actividad pública y privada destinada a la colonización con inmigrantes y establecer los mecanismos necesarios para el registro y contralor de tales actividades, a fin de asegurar que se desarrollen de manera beneficiosa para el país y para los inmigrantes que se instalen por su intermedio.

En esta ley se observa que el Estado es el que debe fomentar la inmigración "deseada", asentar territorialmente, dar trabajo y alojar, así como castigar a aquellos nacionales que asistan o empleen a los extranjeros. Igualmente faculta al Ministerio del Interior para disponer la expulsión de la República de todo extranjero, cualquiera sea su situación de residencia, cuando: "resulte condenado 
por Juez o Tribunal argentino, por delito doloso o pena privativa de libertad mayor de Cinco (5) ańos; b) realizare en el país o en el exterior, actividades que afecten la paz social, la seguridad nacional o el orden público de la República."

Esta nueva norma incorpora la distinción entre "ilegalidad por ingreso" e "ilegalidad por permanencia" (Decreto $\mathrm{N}^{\circ} 4.805 / 63$ ). Define tres categorías de ingresos: residentes permanentes, temporarios y transitorios, y afirma el goce de derechos constitucionales para los primeros. Solamente en el artículo 15, el que alude a los extranjeros "residentes permanentes" se explicita que tendrán los mismos derechos civiles que los argentinos:

Los extranjeros admitidos en la República como "residentes permanentes", así como los que obtengan autorización de permanencia en tal carácter, gozan en su territorio de los derechos civiles de los argentinos, sujetos a iguales obligaciones y deberes. El ejercicio del derecho de entrar, permanecer, transitar y salir del territorio, se subordinará a las disposiciones de la presente ley y de sus reglamentaciones.

No obstante, en este periodo, los derechos civiles de los argentinos también se encontraban vulnerados por la normativa mencionada y por las prácticas represivas estatales concretas. Por lo tanto, la proclamación de los derechos civiles de los extranjeros tampoco se podía asociar con su realización plena.

Un dato muy importante -que indica la pretensión de complicidad por parte de toda la sociedad - es la extensión de la obligatoriedad de denuncia en caso de permanencia ilegal para hospitales, centros asistenciales, escribanos y escuelas. De esta manera, se habilita a la DNM para: "entrar libremente y sin notificación previa a los lugares o locales comerciales, industriales, educacionales, hospitalarios, asistenciales y todo aquel en el que exista o medie repunciones de infracción de la presente ley (Art. 107, inciso c).”

En resumen, en esta ley se sintetiza la apelación a un "ser nacional" y a un proyecto de nación basados en una pretendida homogeneidad étnica, política, ideológica y cultural que sería impuesta por el aparato estatal, puesto que toda nación carece de dicha condición pero, sin embargo, ésta forma parte de sus mitos constitutivos. La importancia que los gobiernos militares le otorgaron a las políticas de población parece encajar perfectamente con el ideal de sociedad y de nación a las que aspiraban, para las que el control y la intervención constituían variables determinantes para llevar a cabo sus proyectos nacionales.

Siguiendo a Olego de Campos (1990), se debe destacar que una preocupación especial del gobierno militar estuvo constituida por la influencia de extranjeros asiáticos en el país (fundamentalmente de Corea del Sur y de Taiwán), pues se consideraba que su número y sus características étnicas y culturales podían representar un "riesgo para la unidad y seguridad de la nación”. Estos supuestos 
determinaron la adopción de un mecanismo de ingreso colectivo representado por la figura de los "proyectos de inversión y desarrollo de actividades productivas". Este procedimiento incluye de manera implícita un criterio de política basado en la proporción admisible de población perteneciente a estas nacionalidades en términos cuantitativos. Olego de Campos (1990) explica que el Anexo II de la resolución de carácter secreto No 0506/81 de la DNM constituye el antecedente de este mecanismo de ingreso.

Otro aspecto a destacar es la forma en que se han ejercitado las facultades conferidas por el Poder Ejecutivo para determinar los criterios de admisibilidad y selección de extranjeros. La fijación de estos criterios mediante resoluciones ha sido una práctica casi constante de la DNM. En este contexto, conviene analizar el lugar de dicho organismo, dependiente de la Secretaría de Población del Ministerio del Interior, porque son evidentes sus facultades excesivas que incluyeron no sólo el derecho de admisión y administración de las políticas migratorias, sino además el derecho de "controlar el ingreso, egreso y permanencia y ejercer el poder de policía de extranjeros en todo el territorio de la República" (Ley 22.439, Art. 40). En particular, esta ley faculta a un organismo administrativo dependiente del Poder Ejecutivo para allanar los lugares con sospecha de presencia de inmigrantes ilegales, para detenerlos y expulsarlos (Ley 22.439, Arts. 107, 40, 37 y 38). Resulta alarmante en materia de derechos humanos de las personas migrantes la actuación de la Policía Migratoria Auxiliar que trabajaba bajo las directivas de la DNM (CELS, 1999: p. 35).

En resumen, en el "proyecto nacional" al que aspiraba la Junta Militar del Proceso se encontraba implicado — aunque probablemente no fuera más que de manera tácita- un conjunto de ideas directrices sobre la naturaleza del "ser nacional". De este modo, la Ley Videla constituye la cristalización de ese ideario y los esfuerzos para instituirlo. Las restricciones establecidas a los inmigrantes pueden ser entendidas en el marco general de una política de supuesta "protección a la esencia del ser nacional" por varios motivos: a) establecen las características culturales deseables que debería comportar aquél que quisiera incorporarse a la sociedad argentina siendo extranjero; $b$ ) se intenta diseñar una fuerte política de protección y persecución de los "indeseables", a través de la penalización del ingreso irregular, la obligatoriedad de la denuncia de la presencia de ilegales en todo organismo público, la denegatoria de uso de los servicios públicos (como la salud y la escolarización), etc. Estas medidas contienen las nociones de la composición social que pretendía perpetuar el gobierno militar, entre las que la promulgación de la Ley Videla es un claro ejemplo. ${ }^{7}$

7 No obstante, esta ley no incluyó un reglamento migratorio, por lo que continuó en vigencia el Decreto № 4.418/65 hasta la sanción del regulatorio de 1987. 
En las construcciones nacionales que se refuerzan a partir de la figura del migrante son marcados los efectos que el modelo migratorio de la dictadura pretendía producir al nutrirse de múltiples enemigos: por un lado, el inmigrante limítrofe —en tanto aquel otro "enemigo externo" que atentaba culturalmente contra las bases (ficticias) sobre las que se asentaba la nación-; por otro, el "enemigo interno", representado por el "subversivo" que desafiaba los presupuestos ideológicos impuestos por el régimen al que por consiguiente había que exterminar o expulsar. A partir de este momento se funda una lógica particular para elaborar políticas migratorias que involucra, además de una preocupación creciente en torno a la seguridad interior y exterior, un modelo migratorio que abarca el plano ético, sociojurídico, normativo, político y social.

\section{Referencias}

Anderson, B. (1993). Comunidades imaginadas. Reflexiones sobre el origen y la difusión del nacionalismo. México: Fondo de Cultura Económica.

Balibar, E. (1991). La forma nación: historia e ideología. En Balibar, E. \& Wallerstein, I. Raza, nación y clase. Madrid: IEPALA, 135-167.

Barros, S. (2003). Violencia de Estado e identidades políticas. Argentina durante el proceso de Reorganización Militar. Amnis. Revue de Civilisation Contemporaine Europes/Amériques. pp. 1-21. Recuperado el 15 de septiembre de 2006, de http://www.univ-brest.fr/amnis/

Bonora, V. (2007). "La normativa migratoria y los procesos de exclusión en Argentina”, en: IV Jornadas de Jóvenes Investigadores, Instituto de Investigaciones Gino Germani, Facultad de Ciencias Sociales, Universidad de Buenos Aires, Buenos Aires, 19, 20 y 21 de septiembre de 2007. Recuperado el 10 de julio de 2009, de http://www.iigg.fsoc.uba.ar/jovenes_ investigadores/4jornadasjovenes/EJES/Eje\%201\%20Identidades\%20Alteridades/ Ponencias/MARTINEZ\%20BONORA,\%20Virginia.pdf

Botana, N. (1994). El orden conservador. La política argentina entre 1880 y 1916. Buenos Aires: Editorial Sudamericana.

Brubaker, R. (1992). Citizenship and Nationhood in France and Germany. Cambridge: Harvard University Press.

Calveiro, P. (1998). Poder y desaparición. Los campos de concentración en Argentina. Buenos Aires: Colihue. 
Cavarozzi, M. (2002). Autoritarismo y democracia. Buenos Aires: Editorial Universitaria de Buenos Aires.

Centro de Estudios Legales y Sociales (CELS). (1999). Inmigración, politica estatal y vigencia de los Derechos Económicos, Sociales y Culturales de los inmigrantes y trabajadores migratorios peruanos y bolivianos en Argentina. Buenos Aires: CELs.

Cook Martín, D. (2005, 7 de abril). Proactive Recruitment and Retentionist Patterns of Migration and Nationality Policy in Argentina, Italy and Spain (1850-1919). Investigación presentada en el Comparative Social Analysis Seminar del Department of Sociology, University of California, 75 .

Courtis, Corina. (2006a). Hacia la derogación de la Ley Videla: la migración como tema de labor parlamentaria en la Argentina de la década del 90. En Jelin, E. \& Grimson, A. (Comps.). Migraciones regionales hacia la Argentina. Diferencia, desigualdad y derechos (pp. 169-205). Buenos Aires: Prometeo Libros.

Courtis, Cristian. (2006b). Detrás de la Ley. Lineamientos de análisis ideológico del derecho. En Courtis, C. (Ed.). Observar la ley. Ensayos sobre metodología de la investigación jurídica. Madrid: Editorial Trotta.

Documentos Básicos y Bases Políticas de las Fuerzas Armadas para el Proceso de Reorganización Nacional, Buenos Aires, 1980.

Duhalde, E. L. (1999). El Estado Terrorista Argentino. Quince años después, una mirada crítica. Buenos Aires: Eudeba.

Escudé, C. \& Cisneros, A. (2000). Historia general de las relaciones exteriores de la República Argentina. Buenos Aires: GEL.

Ferrer, A. (2008). La economía argentina desde sus origenes hasta principios del siglo XXI. Buenos Aires: Fondo de Cultura Económica.

Feierstein, D. (2007). El genocidio como práctica social. Entre el nazismo y la experiencia argentina. Buenos Aires: Fondo de Cultura Económica.

Gil Araujo, S. (2006). Las argucias de la integración: Construcción nacional y gobierno de lo social a través de las políticas de integración de inmigrantes. Los casos de Cataluña y Madrid. Tesis doctoral, Universidad Complutense de Madrid, Madrid.

Grimson, A. (2003). La vida política de la etnicidad migrante: Hipótesis en transformación. Revista de Estudios Migratorios Latinoamericanos, 17(50), 143-159.

L. S. Nejamkis | Políticas migratorias y dictadura militar en Argentina (1976-1983): la construcción de un modelo migratorio | Perfiles Latinoamericanos, 24(47) | FLACso México | pp. 7-29 | DoI: 10.18504/pl2447-001-2016 
Groisman, E. (1983). Poder y derecho en el proceso de reorganización nacional. Buenos Aires: CISEA.

López Chirico, S. (1985). Tres formas de dominación oligárquica latinoamericanas: Argentina, Brasil, Perú. Dialéctica, 17, [en línea], recuperado de http://148.206.53.230/revistasuam/ dialectica/

López Salas, A. M. (2005). Inmigrantes y Estados: la respuesta politica ante la cuestión migratoria. Barcelona: Anthropos.

Novaro, M. \& Palermo V. (1996). Política y poder en el gobierno de Menem. Buenos Aires: Norma.

Novick, S. (1986, abril). Las políticas inmigratorias en su expresión jurídica. Una perspectiva secular. Estudios Migratorios Latinoamericanos (CEMLA), 2, 470-490.

Olego de Campos, S. (1990). Migraciones internacionales: Politicas implementadas en la Argentina entre 1980 y 1990. Documento presentado en el seminario "Argentina, reforma constitucional y ordenamiento legislativo en materia de población”, Buenos Aires.

Pacecca, M. I. (2001). Migrantes de ultramar, migrantes limítrofes. Políticas migratorias y procesos clasificatorios. Argentina, 1945-1970. En "Informe final del concurso 'Culturas e identidades en América Latina y el Caribe. Programa Regional de Becas CLACso”, [en línea], recuperado de http://bibliotecavirtual.clacso.org.ar/ar/libros/becas/2000/pacecca.pdf

Pérez Vichich, N. (1988, diciembre). Las políticas migratorias en la legislación argentina. Y para todos los hombres del mundo... Estudios Migratorios Latinoamericanos (CEMLA), 10, 441-464.

Rapoport, M. (2006). Historia económica, politica y social de la Argentina. Buenos Aires: Ariel.

Romero, L. A. (2005). Breve historia contemporánea de la Argentina. Buenos Aires: Fondo de Cultura Económica.

Sassone, S. (1987, agosto). Migraciones ilegales y amnistías en la Argentina. Estudios Migratorios Latinoamericanos (CEMLA), 6-7, pp. 249-290.

Sayad, A. (1999). La Double Absence. Des illusions de l'émigré aux souffrances de l'immigré. París: Liber/Senil.

Segato, R. (2007). La Nación y sus Otros. Raza, etnicidad y diversidad religiosa en tiempos de politicas de identidad. Buenos Aires: Prometeo Libros.

Sirlin, E. (2007). La última dictadura militar: genocidio, desindustrialización y recurso de guerra (1976-1983). En De Luque, S. et al., Pasados presentes: política, economía y conflicto social en la historia argentina contemporánea. Buenos Aires: Dialektik Editora. 
Treves, R. (1998). La sociología del derecho. Orígenes, investigaciones, problemas. Barcelona: Ariel.

Vior, E. (2007). ¿Cambia la visión de los derechos humanos de una cultura a otra? En C.A. Lértora Mendoza, C. A. (Coord.). Evolución de las ideas filosóficas 1980-2005. XIII Jornadas de pensamiento filosófico. Buenos Aires: FEPAI.

Recibido el 19 de abril de 2012. Aceptado el 28 de octubre de 2014. 